\title{
The Lush Prize and Young Researcher Asia Awards 2016
}

\author{
Rebecca $\operatorname{Ram}^{(\bowtie)}$ \\ Clinical Data Scientist and Scientific Research Consultant-Lush Prize, London, \\ UK \\ rebecca@lushprize.org \\ http://lushprize.org
}

\begin{abstract}
The Lush Prize is now in its fifth year and awards a total of $52,000,000 \mathrm{JPY}$ (approx.) annually to initiatives working to end the use of animals in toxicology testing. There are six categories of award: Science; Training; Young Researcher; Lobbying and Public Awareness. The sixth category is the Lush Black Box Prize which offers, in any one year, a further 38,000,000 JPY (approx.) for a key breakthrough in human toxicology. Many initiatives are directed at the '3Rs': reduction, refinement, and replacement of the use of animals. The Lush Prize seeks only to support projects working on the genuine replacement of animal tests and is the largest reward in its field [1].

In 2016, the Prize is very pleased to announce the launch of its Young Researcher Asia awards, to welcome young scientists from across Asia, up to 35 years old at time of application, who wish to pursue a career in animal-free toxicology. Applicants complete a nomination explaining their research proposals, including how they would use a bursary of approx. 1,400,000 JPY. To date in 2016, a total of 37,800,000 JPY has been awarded to nineteen international young researchers for 21 st century human-relevant toxicology projects.

The Lush Prize continues to welcome nominations from across the Asia region, not only for Young Researcher awards, but all other prize categories. This report aims to provide an overview of the Prize, the categories of award available, achievements to date and further background information.
\end{abstract}

\section{Introduction}

The Lush Prize was developed to address two urgent goals; firstly, to fund the development of modern, more reliable methods of human-relevant safety testing and secondly but equally importantly, to replace unreliable and inhumane animal tests.

Many scientists find that access to funding for research into non-animal technologies can be a barrier. The Lush Prize wants to change this and encourage young researchers to develop a career in toxicology without harming animals, by offering bursaries to allow them to advance in this area. The Lush Prize is now in its fifth year and awards an annual total of 52,000,000 JPY (approx.) to initiatives working to end the use of animals in toxicology testing. There are six categories of award: Science; Training; Young Researcher; Lobbying and Public Awareness. The sixth category is 
the Lush Black Box Prize which offers, in any one year, a further 38,000,000 JPY (approx.) for a key breakthrough in human toxicology. An overview of the different categories is provided below.

\section{The Lush Prize Categories}

1. Science - For individuals, research teams or institutions for work conducted on relevant toxicity pathways. Outstanding research producing an effective non-animal safety test based on an approach other than toxicity pathways, where none existed before, may also be considered.

2. Young Researchers - Open to scientists (up to 35 years of age at the time of application) with a desire to fund the next stage of a career in animal free toxicology. (The annual YR prize fund is usually divided between five winners, each awarded approx 1,400,000 JPY). The Young Researcher prizes are distinct from other categories as they awarded on the basis of future research proposals, intended to replace the use of animals. All other categories of prize are awarded on the basis of past activities and achievements, over the previous 12-18 months.

The Science and Young Researcher Prizes are designed to advance direct research into non-animal technologies. The Lush Prize is pleased to launch the Young Researcher Asia Awards at the 2016 JSAAE Congress.

3. Training - For individuals, teams or organisations involved in training others in non-animal methods. There remains an ongoing, urgent need for education and training in the use of widely available, human-relevant, non-animal technologies; communication on this is vital and remains an obstacle to change. Many establishments or individuals may not have been trained in available, animal-free methods or might not even be aware of them, while future scientists and students need to be provided with education in alternative methods, in order to be able to pursue further research in this area. This prize recognises the importance of relevant information and hands-on training among commercial scientists, researchers and students.

The Training Prize is designed to aid resource for projects training scientists or regulators in non-animal methods.

4. Lobbying - The Lobbying prize rewards exceptional individuals, groups or organisations pushing for change, focusing on policy interventions promoting the replacement or end of animal tests. These may include science-based lobbying at national or international level, for example to recognise non-animal testing methods in national or international (e.g. Organisation for Economic and Cooperative Development (OECD) programmes of test guidelines [2], removal of animal tests and achieving mandatory requirements for non-animal methods in legislation, regulatory policies and testing guidelines.

5. Public Awareness - Organisations and individuals working to raise awareness on both the ongoing suffering associated with animal testing and the scientific need for 
its replacement are recognised by the Public Awareness prize. Winners are awarded for their work in ensuring that these issues remain high on the public agenda.

The Public Awareness and Lobbying Prizes are designed to maintain pressure and influence, to ensure regulation is updated to reflect advances in 21 st-Century toxicology.

\section{The Black Box Prize}

A special sixth category of prize is the Black Box Prize. It may offer a full 38,000 000 JPY (approx.) in any one year, for a key breakthrough in research into pathways of human toxicity in response to chemicals, replacing the use of animals.

The first Black Box prize was awarded in 2015, to several individuals and organisations for their achievements in the development of new in-vitro test methods which elucidated the Adverse Outcome Pathway (AOP) for skin sensitisation, now accepted at OECD level [3].

\section{The Lush Prize Is a ' $1 R$ ' Initiative}

Many funding schemes are devoted to 'the 3Rs'; Reduction, Refinement, Replacement of the use of animals in experiments. However, as 'reduction' and 'refinement' methods still involve animals, the Lush Prize only supports projects working towards the ' $1 \mathrm{R}$ ' - the complete replacement of animal tests. It is the largest prize fund in the world devoted to this initiative.

\section{Launch of Lush Prize 'Young Researcher Asia' Awards in 2016}

In 2016, the Prize is very pleased to announce the launch of its Young Researcher Asia Awards and welcomes young scientists from across Asia, up to 35 years old at time of application, who wish to pursue a career in animal-free toxicology. Applicants complete a nomination explaining their research proposals, including how they would use a bursary of approx. 1,400,000 JPY. To date in 2016, a total of 37,800,000 JPY has been awarded to nineteen international young researchers for human-relevant toxicology projects. Our 2016 Young Researcher Award winning projects [4] include research themes of;

- Development of innovative 3D human skin models to test cosmetics

- Human tissue-derived test methods to assess how chemicals cause hepatotoxicity

- Establishment of human based in vitro methods to test dental and medical devices.

\section{Projects Funded by the Lush Prize to Date}

- 8 international scientific organisations for projects including human lung cancer tissue culture models, body-on-a chip systems, 'omics' technology-derived data 
from analysis of human in-vitro and in-silico models, QSARs (Quantitative Structure Activity Relationships) and work on toxicity pathways in heptatoxicity and developmental toxicity.

- 32 young researchers and early career scientists from across the world, with bursaries totalling more than 40,000,000 JPY.

- 8 outstanding Training prize winning organisations, for projects including preparation and delivery of training workshops and webinars, outreach and communication in universities and educational establishments across the world and direct delivery of 'hands-on' training in non-animal methods in China.

- 11 Public Awareness projects (total more than 45,000,000 JPY) for breakthrough investigational campaigns highlighting the suffering of non-human primates, cats and dogs; initiatives to end toxicity testing in the USA, Switzerland, China, Russia, Canada and Japan and finally, campaigns on banning animal tested cosmetics in Taiwan, Australia and New Zealand.

- 10 Policy makers, political figures and scientific organisations devoted to alternatives to animal testing from the USA, Sweden, Germany, New Zealand, Brazil and India have been awarded more than 45,000,000 JPY in Lobbying Prize funding to date.

Since its launch in 2012, the Lush Prize has awarded over 210,000,000 JPY to bring forward the day when safety testing takes place using only human- based methods, without animals.

Past nominations have been welcomed from across Japan, South Korea, China, Taiwan, Singapore and Malaysia. In 2016, a record number of nominations 55 projects/scientists from 21 countries, including Japan, South Korea, China and Singapore [5]. The prize welcomes many future nominations from across the Asia region and worldwide.

Many initiatives are directed at the '3Rs': reduction, refinement, and replacement of the use of animals. The Lush Prize seeks only to support projects working on the genuine replacement of animal tests and is the largest reward in its field.

Nominations open for the Lush Prize open in March each year. Any individual(s) or organisation who wish to apply must submit a full nomination form by the June deadline. Judging is carried out by an independent panel of experts from around the world - scientists, lobbyists and campaigners. Winners participate in a conference and attend a prestigious awards ceremony. Full details of the Young Researcher Award [6] and other award categories are available on the Lush Prize website [1].

\section{References}

1. The lush prize (2017). http://lushprize.org/. Accessed 15 Dec 2017

2. OECD (Organisation for Economic Co-operation and Development) (2017). http://www. oecd.org/chemicalsafety/testing/oecdguidelinesforthetestingofchemicals.htm. Accessed 15 Dec 2017

3. The adverse outcome pathway for skin sensitisation initiated by covalent binding to proteins (2017). http://www.oecd.org/env/the-adverse-outcome-pathway-for-skin-sensitisationinitiated-by-covalent-binding-to-proteins-9789264221444-en.htm. Accessed 17 Dec 2017 
4. Young researcher Asia (2016). http://lushprize.org/2016-prize/2016-young-researcher-asia. Accessed 17 Dec 2017

5. The lush prize; past years. http://www.lushprize.org/past-years/. Accessed 17 Dec 2017

6. Young researcher prize. http://www.lushprize.org/awards/young-researcher-prize/. Accessed 17 Dec 2017

Open Access This chapter is licensed under the terms of the Creative Commons Attribution 4.0 International License (http://creativecommons.org/licenses/by/4.0/), which permits use, sharing, adaptation, distribution and reproduction in any medium or format, as long as you give appropriate credit to the original author(s) and the source, provide a link to the Creative Commons licence and indicate if changes were made.

The images or other third party material in this chapter are included in the chapter's Creative Commons licence, unless indicated otherwise in a credit line to the material. If material is not included in the chapter's Creative Commons licence and your intended use is not permitted by statutory regulation or exceeds the permitted use, you will need to obtain permission directly from the copyright holder. 